\title{
Kasvatusantropologisen tutkimuksen havaintoja kehitysyhteistyön koulutuksesta
}

\author{
Soila Judén-Tupakka
}

\author{
Jos kehitysyhteistyön intervention tavoitteleman \\ kehityksen kohdetta, sen toimintakulttuuria ja ajattelua \\ ei tunneta, ei myöskään tiedetä, mitä kehitetään tai \\ millaista muutosta toiminnan seurauksena syntyy. Silloin \\ ei myöskään tiedetä, mitä kehitys on tai mihin suuntaan \\ kehityksen tulisi johtaa.
}

E räs kehitysyhteistyön koulutuksen kohteista vat kehitysmaiden kyläkätilöt, joille useat eri organisaatiot ovat tarjonneet aikuiskoulutusta. Kyläkätilöt toimivat tavallisesti irrallaan virallisesta terveydenhuolto-organisaatiosta, mutta heitä pyritään liittämään sen valvontaan. Egyptissä kyläkätilöitä kutsutaan dayoiksi. Vaikka kehitysmaiden perinteisiä lapsenpäästäjiä kutsutaan kyläkätilöiksi, eivät esimerkiksi dayat ole ainoastaan länsimaisin termein määriteltyjä kätilöitä, vaan he hoitavat monipuolisesti naisen elämänkaaren siirtymiä kehdosta hautaan. Dayat hoitavat mm. kotisynnytyksiä, järjestävät lapsen nimenantojuhlan, suorittavat tyttöjen ympärileikkauksia, puhkaisevat morsiamen immenkalvon ja pesevät naisten ruumiita. (Judén-Tupakka 1995; 2000.)

Dayoja on koulutettu suomalais-egyptiläisen kehitysyhteistyöprojektin yhteydessä. Tutkimuksessani (Judén-Tupakka 2000) olen pyrkinyt ymmärtämään muun muassa sitä, mitä dayat, yläegyptiläiset rituaaliset kyläkätilöt, itse kertovat asemastaan ja siitä, keitä he ovat ja mitä he tekevät. Tämän tiedon kerääminen ei olisi ollut mah- dollista ilman vuorovaikutusta dayojen kanssa. Suomalais-egyptiläisen kehitysyhteistyöprojektin kehitysintervention koulutuksellisena tavoitteena oli integroida daya viralliseen egyptiläiseen terveydenhuoltojärjestelmään. Kehitysyhteistyöprojektissa terveysasemien kätilösairaanhoitajat ja lääkärit kouluttivat dayoja, joiden tuli siirtyä virallisen terveydenhuolto-organisaation valvontaan. Koulutuksessa havaittiin kuitenkin, että terveysasemien henkilökunnan oma ammatillinen osaaminen oli sellaista, että heidän ei voitu ajatella opettavan dayoja ilman täydennyskoulutusta. Siksi dayoista piti tehdä koulutustoiminnan välineitä eli syy siihen, miksi virallisen järjestelmän jäseniä piti kouluttaa. (Judén-Tupakka 1993; 1995; 2000.)

Tarkastelen esityksessäni kehitysyhteistyötä ja siihen liittyvää vieraassa kulttuurissa tapahtuvaa koulutusta kasvatusantropologisena kysymyksenä.

\ehitysyhteistyö nähdään osana Suomen viXrallista ulkopolitiikkaa. Suomen kehitysyhteistyön tunnettuja tavoitteita ovat köyhyyden 
vähentäminen, ympäristön suojeleminen, tasaarvon edistäminen sekä demokratian ja ihmisoikeuksien puolustaminen. Nämä ovat periaatteita, jotka pitäisi ottaa huomioon kehitysyhteistyöprojektien suunnittelussa, toteutuksessa, seurannassa ja arvioinnissa. (Ks. Guidelines..., 1998.)

Tutkimustani sivuava kehitysyhteistyöprojekti käynnistyi 1980-luvulla ja sitä koskeva tutkimusaineisto kerättiin vuonna 1994. Tämän jälkeen on kehitysyhteistyöprojektien ohjeistuksiin tehty muutoksia ja toiminnassa on myös pyritty ottamaan paremmin huomioon muiden tavoitteiden ohella sosiaalista sukupuolta koskevat kysymykset sekä kulttuurin merkitys koko kehitysyhteistyöhankkeen aikana (Ks. Seppälä \& VainioMattila 1999; Vainio-Mattila 1999).

Ohjeistuksissa vaaditaan kulttuurin sisällyttämistä projekteihin. Ohjeissa esitetään luetteloina asioita, joita tulisi ottaa huomioon, kun kehityshankkeita suunnitellaan, toteutetaan, seurataan ja arvioidaan. (Suomen kehitysmaapolitiikan linjaus 1999, 6-8, 21-33; Kehitysyhteistyön periaatepäätös 1999 , 6-9; Guidelines for... 1998, 1.) Niissä kehitys nähdään interventiona, jolla saadaan aikaan halutunlaista muutosta kehitettävässä kohteessa (ks. esim. Guidelines for... 1998, 1). Sanana interventio sisältää ajatuksen ulkopuolisesta puuttumisesta johonkin (Uusi sivistyssanakirja, 1992).

Suomen kehitysyhteistyössä hyvää tarkoittavaa kehitystä katsotaan syntyvän, kun tavoitteisiin pyrkiviä toimia suunnataan kehitettävään kohteeseen tietyn intervention avulla. Yksi näistä toimista on jo pitkään ollut erilainen koulutustoiminta kohdemaassa.

Kehityksen voidaan siis ajatella syntyvän intervention tuloksena. Toisaalta kehityksen on myös ajateltu olevan köyhyyden poistamista ja talouskasvua. Jos ulkopuolelta asetetut kehitystavoitteet ja -keinot ovat olleet absurdeja kehitettävässä kohteessa, on myös pyydetty, että kehitys lopetettaisiin. (Ks. esim. Takala 1989; Alvares 1991.) Näiden lisäksi kehitystä voidaan ajatella myös ihmisen tai yhteisön oppimisena, jossa edistys tapahtuu muun muassa uuden tiedon, ajatustapojen ja toimintatapojen sisäistämisenä.

\section{Oppija on aktiivinen toimija kulttuurisessa ympäristössään}

un sisäistettyjä asioita reflektoidaan ja koKeillaan käytännössä ja ne todetaan toimiviksi, käyttäytymisessä saattaa tapahtua muutosta. Oppiminen tapahtuu kuitenkin aina myös sosiaalisessa ja kulttuurisessa ympäristössä, jossa ihminen aktiivisesti käsittelee ja rakentaa käsityksiään sekä tietoa oman aikaisemman tietovarastonsa perusteella. (Vrt. myös Jarvis 1987; Mezirow \& al. 1995; Engeström 1998; Berger \& Luckmann 1994.) Sosiaalisen ja kulttuurisen ympäristön merkitys oppimisessa ja opettamisessa korostuu silloin, kun toimitaan vieraassa kulttuurissa.

Oppiminen ei tapahdu umpiossa, vaan uutta oppivalla henkilöllä on jo muun muassa aikaisempaa tietoa, taitoa, kokemusta ja ajatusrakennelmia, joiden perusteella hän aktiivisesti käsittelee oppimaansa. Hän ei ota vastaan passiivisesti häneen suunnattuja toimia ja oppeja, vaan hän pyrkii konstruoimaan tietoaan ja kokemustaan. Pitäisikö silloin kehitettävän ihmisen tai maan olla kehitystoiminnan intervention subjekti vai objekti? Vai pitäisikö kehitystoiminnan ollakin intervention sijasta vuorovaikutusta?

Jos ajatellaan kehittymisen tai kehityksen olevan seurausta jostain opitusta, interventioon perustuvaa kehitys- tai oppimismallia voidaan ajatella panos-tuotos-relaationa, jossa intervention kohteella on passiivinen positio. Oppimisen termein ajatellen tällaisen lähestymisen voidaan katsoa 
Yläegyptiläinen sairaanhoitaja esittelee Unicefin lahjoittaman kätilölaukun työkalujen sterilointia.

olevan lähellä behavioristista oppimisnäkemystä. Behaviorismi pyrkii siihen, että ulkopuolelta ohjattu ja annettu tieto sekä kehitys suunnataan panoksena kohteeseen, jossa halutaan saavuttaa tavoitteiden mukaista päätekäyttäytymistä. Käytännössä kehitettävä kohde, jos hänet halutaan nähdä kohteena, ei koskaan omaksu oppimaansa kuin tyhjä taulu, vaan hänellä on oma tapansa käsitellä tietoa. Perinteisessä kulttuurissa tämä tapa saattaa olla esimerkiksi rituaalinen.

$\mathrm{M}$ itä vuorovaikutuksen puute ja behaviorisinen päätekäyttäytymiseen perustuva opetusmalli sitten voivat käytännössä tarkoittaa? Vuorovaikutuksen puute voi näkyä esimerkiksi siinä, että kehitysyhteistyön koulutukseen valittu oppimateriaali on koulutettaville täysin käsittämätöntä. Jordan (1989) on tutkinut kyläkätilöitä muun muassa Jukatanin niemimaalla EteläAmerikassa. Hän seurasi kyläkätilöiden koulutusta ja keskusteli heidän kanssaan taukojen aikana. Jordanille selvisi esimerkiksi, että kyläkätilöt eivät ymmärtäneet opetukseen valmistettua kuvamateriaalia, vaan tekivät näkemästään omia johtopäätöksiään. Hän kertoo esimerkin siitä, kuinka kyläkätilöt ymmärsivät opetusta varten tehdyn hedelmöittymistä esittävän kuvataulun sanoen: "Ei meillä tarvita mitään erityisiä palloja ja sauvoja, kuten meksikolaiset ja gringot tarvitsevat." (Jordan 1989, 928.)

Egyptissä observoimassani kehitysyhteistyöprojektin koulutuksessa dayoille suunnatun kurssin opetussuunnitelmassa ja -tavoitteissa käsiteltiin esimerkiksi dayan työkalulaukun, niin sanotun dayakitin, sisältämien työvälineiden sterilointia (ks. Daya Training Programme. Trainer's Guide. 1987, 40, 42-43). Samoin dayoille suunnattu kuvakirja eli Daya Atlas esittää, kuinka työvälineet keitetään priimuskeittimellä tai liekitetään spriillä kaarimaljassa (Daya Atlas. (S.A.) 1982, 19). Opetuksessa neuvotaan keittämään välineitä 1020 minuuttia. Opetuksen tavoitteena on, että dayat osaavat steriloida Unicefiltä lahjaksi saamansa työkalut.

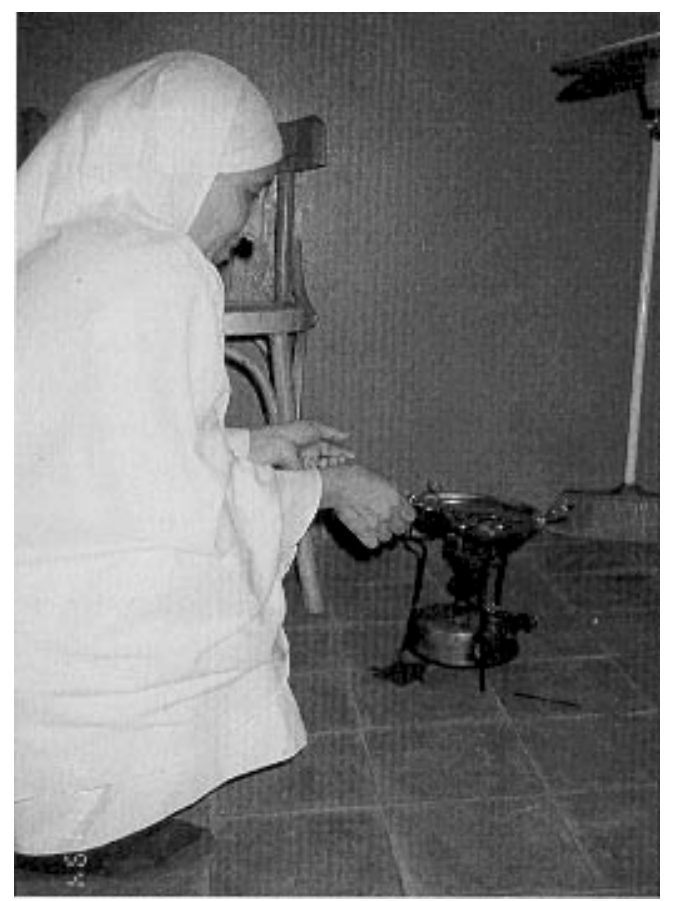

Tähän tavoitteeseen liittyen kerron omasta aineistostani esimerkin oppimisesta, jossa seurataan annettuja ohjeita, mutta koska tietoa ei ole sisäistetty, ovat sinänsä oikean toiminnan seuraukset traagisia.

Kuvassa erään yläegyptiläisen terveysaseman sairaanhoitaja näyttää dayakoulutuksen yhteydessä, miten Unicefin dayakitin työkalut steriloidaan. Opettajan ohjeissa kerrotaan, että dayoja on neuvottava ottamaan aikaa, jotta varmistetaan välineiden steriloituminen. Dayoilla ei ole kelloja, mutta he eivät myöskään osaisi niitä käyttää. Sairaanhoitajalla on kello, ja hän näyttää, mitä ajanotolla tarkoitetaan steriloinnin yhteydessä. Ennen kuin steriloitumiseen tarvittava aika on kulunut, kuuma ilmanala ja kerosiiniliekki ovat kuitenkin haihduttaneet veden kaarimaljasta, jossa työkalut ovat. Jotta ohjeissa määrätty kelloaika täyttyisi, sairaanhoitaja lisää astiaan uutta vettä ja jatkaa samalla tarkasti ajanottoa. Kun säädetty 20 minuuttia on kulunut, hän lopettaa steriloinnin, vaikka uusi vesi on juuri vasta alkanut kiehua. Esimerkki kertoo, kuinka sairaanhoitaja opettaa dayoille sterilointia saamiensa ohjeiden mukaan, mutta hän ei ole itse sisäistänyt ensinkään sitä, mitä steriloiminen tarkoittaa. Sairaan- 
hoitaja on itse oppinut rituaalin, joka pitää suorittaa, jotta saadaan halutunlaista puhdasta.

\section{Vuorovaikutukseen perustuva tutkimuksellinen työtapa}

$\mathrm{J}_{\mathrm{m}}^{\mathrm{o}}$ os kehitysyhteistyön intervention tavoitteleman kehityksen kohdetta, sen toimintakulttuuria ja ajattelua ei tunneta, ei myöskään tiedetä, mitä kehitetään tai millaista muutosta toiminnan seurauksena syntyy. Silloin ei myöskään tiedetä, mitä kehitys on tai mihin suuntaan kehityksen tulisi johtaa. Ajatus siitä, että kehitysmaassa tehdään kehitysinterventioita, saattaa asettaa ihmiset passiiviseksi kohteiksi, jolloin tiedon liittäminen jo olevaan tietoon sekä tiedon soveltaminen ja käyttöönotto jäävät oppijan itsensä varaan. Puutteellisissa olosuhteissa elävät ihmiset ovat itse oman elämänsä asiantuntijoita, mutta he eivät välttämättä osaa yksin tuottaa sellaista tietoa, jota voitaisiin hyödyntää kehityshankkeissa.

Köyhyyden vähentäminen, ympäristön suojelu, tasa-arvon edistäminen sekä demokratian ja ihmisoikeuksien toteutuminen ovat kaikki kiinteässä yhteydessä kehitysmaiden naisten asemaan ja sen parantamiseen. Kuitenkin naisia koskevien asioiden huomioonottaminen on vaikeaa, koska ei välttämättä tiedetä, mitkä toimet edistävät tai mitkä estävät haluttuja asioita. Saattaa olla, että vaikka kohdemaasta olisi olemassa tutkimuksia, naisia ja tyttöjä koskevaa tutkimusta ei ole tehty.

Kehitysyhteistyössä ratkaisujen täytyy nojata hyväksyttyihin periaatteisiin, joihin kehitystä kuvaavat indikaattorit perustuvat. (Guidelines for... 1998,5 .) Kehitettävästä asiasta ei aina ole aikaisempaa tutkimusta tai se ei ole riittävää. Mistä silloin luodaan arvioitavaan asiaan sopivat indikaattorit? Kuka on pätevä luomaan ne? Taustakartoitukset kehittämiskohteista eivät vielä kerro kohteen sellaisista elementeistä, ominaisuuksista tai positioista, joista ei ole tehty aikaisempaa tutkimusta. Silloin pelkkien aikaisempien tutkimusten referoiminen ei tuota kehityshankkeiden tarvitsemia tietoja toimintansa kohdentamiseksi ja järkeistämiseksi.
Jos ajatellaan, että koulutus, opetus ja kasvatustoiminta ovat kehitysyhteistyön muotoja, olisi tarpeellista tietää, keitä ollaan kouluttamassa.

Kasvatusantropologisen tutkimuksen tarpeellisuus on ilmeinen nyt ja tulevaisuudessa erilaisissa kulttuurien kohtaamistilanteissa, joissa on välttämätöntä saada lisää tietoa kohtaavista kulttuureista ja luoda niiden välille tietoon perustuvia välittäviä rakenteita. Kuitenkaan kohtaamisissa pelkät strukturaaliset välittävät rakenteet eivät riitä, jos kohtaajat puhuvat toistensa ohi ilman, että heidän välilleen syntyy vuorovaikutusta. (Ks. esim. Judén-Tupakka 1995; 2000; Nurmi \& Kontiainen 1995.) Siksi kehitysyhteistyön osapuolien välille pitäisi syntyä kehittävään oppimiseen perustuvaa vuorovaikutusta, jolla on tutkimuksellinen perusta.

Harvat valmiit mallit, ovat ne sitten tutkimusmetodologisia tai hallinnon suunnittelutarpeisiin tehtyjä, toimivat sellaisenaan erilaiseen kulttuuriseen ympäristöön vietyinä. Kehitysyhteistyön perusajatus rakentuu nimenomaan yhteistyölle. Yhteistyö ei kuitenkaan ole interventioita, vaan esimerkiksi vuorovaikutusta, jossa kehitystä tavoitteleva osapuoli on itse osallisena.

Esimerkiksi Vainio-Mattila on pyrkinyt soveltamaan koulutustoimintaan ja siitä annettuun ohjeistukseen niin sanottua osallistavan kehityksen ideaa. (Ks. Vainio-Mattila 1997/1996, 26-27; Laitinen, Voipio \& Grönqvist 1995; Srinivan S. A.; Wilde \& Vainio-Mattila 1995.) Kulttuuriantropologian epistemologisena ajatuksena on se, että ei ole erillistä tutkijaa ja tutkittavaa, ei erillistä subjektia ja objektia, vaan tutkimuksessa tavoiteltava ja tavoitettava tieto on sitä, mikä syntyy vuorovaikutuksessa tutkijan ja tutkittavan välillä (Siikala 1997, 46-68). Silloin ontologiset, ihmistä koskevat oletukset ymmärtävät tutkittavan tutkimustilanteessa aktiiviseksi osapuoleksi. Käytännössä osallistavasta tutkimustavasta (Swantz \& Vainio-Mattila 1988, 127-143) on puhuttu jo pitkään. Tällöin koulutuksen seurauksena tapahtuva oppiminen olisi suunniteltu sen tiedon varaan, joka on seurausta interaktiosta esimerkiksi tutkijan ja tutkittavien välillä. 
Kasvatustieteissä useat erilaiset lähestymistavat käsittelevät nykyisin aikuista ja lasta aktiivisena toimijana, jonka oppimisprosessit perustuvat tiedon sisäistämiseen, rakentamiseen, reflektioon ja toimintaan. Nämä ajatukset puolestaan kertovat siitä, että ihminen nähdään kykeneväksi tuottamaan tietoa, ajattelemaan, oppimaan ja prosessoimaan.

Kasvatusantropologian tulevaisuuden suuntauksiin kuuluu muun muassa Conzálezin (1999, 433-434) mukaan se, että kasvatusantropologinen tarkastelu pitäisi keskittää ihmisten väliseen vuorovaikutukseen, joka usein on luonteeltaan epätasa-arvoista. Vuorovaikutus mahdollisesti auttaa meitä näkemään ja laajentamaan käsityksiämme siitä, mitä ymmärrämme kulttuurin olevan. (González 1999, 433-434.)

Vuorovaikutuksen edistämistä tukevat muun muassa Eisenhartin (1999, 462) käsitykset. Hänen mukaansa uusien kasvatusantropologisten tutkimustulosten perusteella voi sanoa, että meidän pitäisi ottaa entistä paremmin huomioon heidät, jotka ovat suoraan tekemisissä kyseisen asian kanssa. Kasvatus- ja koulutusinterventioissa pitäisi paremmin ottaa huomioon niiden ihmisten tarpeet, toiveet, moraali ja osallistuminen, joita tehdyt ratkaisut koskevat. (Eisenhart 1999, 462.) Kasvatusantropologia onkin siirtymässä muun muassa yksittäisten paikallisten etnisten ryhmien kulttuurin tarkastelusta arkipäivän asioiden intellektuaalisten ilmiöiden ja projektien tutkimukseen (Eisenhart 1999, 462-463; in press).

Kulttuuristen erojen tarkasteleminen on ollut vallitsevana paradigmana kasvatusantropologiassa Yhdysvalloissa. Aikaisemmin kasvatusantropologit ovat pyrkineet ymmärtämään koulutuskohteidensa, esimerkiksi vähemmistöjen lasten kulttuureita. Tarkastelussa on otettu huomioon kulttuuriset erot ja on keskitytty tarkastelemaan mikrointeraktioprosesseja. Huomiota ei ole kiinnitetty valta- ja hegemoniakysymyksiin eikä ole pyritty selvittämään sitä, mitä kulttuuri konkreettisesti on. (González 1999, 432.)

Kasvatusantropologien pitää pystyä tekemään oikeita kysymyksiä. Eräs kasvatusantropologien kiin- nostuksen kohteena oleva kysymys alkavalla vuosituhannella on se, miten ihmiset todella oppivat ja miten oppimiseen vaikuttaa kulttuurinen konteksti, jossa ihmiset ovat kasvaneet. (Hess 1999, 407; Jacob 1997.)

Kehitysyhteistyöprojektien suunnittelun, toteutuksen, seurannan ja arvioinnin tueksi on kehitetty erilaisia indikaattoreita, joiden tavoitteena on helpottaa esimerkiksi sosiaali- ja terveysalan projektien toiminnan tulosten evaluaatiota. Koko projektisyklissä huomioitavaksi tarkoitettujen asioiden listaaminen ei kuitenkaan auta projektin parissa työskentelevää, jos kehitettävästä kohteesta ei ole tietoa, minkä varassa projektin kuluessa huomioonotettavat asiat pitäisi päättää tai toteuttaa. Lisäksi varsinkin naisia koskevat asiat saattavat sisältää niin sanottua hiljaista tietoa, josta ei kulttuurissa ole lupa tai tapana puhua. Saattaa olla, että ne asiat, joista varsinaisesti on kyse, eivät paljastu koko kehitysyhteistyöhankkeen aikana ilman kunnollista perustutkimusta. Miten silloin kehitysyhteistyötä toteuttava konsultti pystyy ottamaan huomioon erilaiset vaaditut indikaattorit? Siksi kehitysyhteistyön yhteydessä tehtävää kasvatusantropologista tutkimusta tarvitaan ainakin kolmella alueella. Kehitysyhteistyöprojekteissa perusselvitysten ja taustakartoitusten lisäksi tarvittaisiin kunnollista perustutkimusta koulutuksesta ja kasvatuksesta kehitysmaissa. Toiseksi tarvittaisiin lisää tietoa naisten ja lasten elämään liittyvistä kasvatusilmiöistä. Kolmanneksi oppimisajatuksiin perustuva tutkimuksellinen työtapa osana projektisykliä saattaisi luoda nopeammin tietoa, jota tarvittaisiin kehitysyhteistyön suunnittelussa, toteuttamisessa, seurannassa ja arvioinnissa.

\section{Lähteet}

ALVARES, Claude. (1991) Lopettakaa kehitys. Imperiumin ulkopuolelta. Kehityskriittisiä puheenvuoroja. Toim. Outi Hakkarainen, Olli Tammilehto \& Thomas Wallgren. s. 254-263. Gaudeamus. Helsinki.

ANDERSSN-LEVITT, Kathryn M. (1999) 30th Anniversary Reflections on the Future Work of Anthropology and Education. Looking Back and Ahead. Anthropology \& Education Quarterly, Vol. 30, nro 4, pp. 430.

BERGER, P. \& LUCKMANN, T. (1994) Todellisuuden sosiaalinen rakentuminen. Tiedonsosiologinen 
tutkielma. Gaudeamus. Helsinki. (Alkuteos: The Social Construction of Reality, 1966.)

CULTURE IN FINNISH DEVELOPMENT CO-OPERATION. (1998) Safa. The Finnish Association of Architects. Ministry of Foreign Affairs (of Finland). Department for Development Co-operation. Helsinki.

DAYA ATLAS. (S.A.) (1982) Prepared by Amira Al Malatawy. Planned by Abdel Fattah Al Badry. UNICEF. El Walid Press. Egypt.

DAYA TRAINING PROGRAMME. TRAINER'S GUIDE. (1987) Ministry of Health (MOH) in Collaboration with United Nations Children's Fund (UNICEF). Prepared by Seham Rageb \& Amira El Malatawy.

EISENHART, Margaret. (1999) Reflections on Educational Intervention in Light of Postmodernism. Anthropology \& Education Quarterly, Vol. 30, nro 4, pp. 462-465.

EISENHART, Margaret. (in Press) Changing Conceptions of Culture and Ethnographic Methodology. Recent Thematic Shifts and Their Implications for Research on Teaching. In the Handbook of Research on Teaching. $4^{\text {th }}$ edition. Ed. Virginia Richardson. American Educational Research Association. Washington, DC.

ENGESTRÖM, Yrjö. (1998) Kehittävä työntutkimus: perusteita, tuloksia ja haasteita. Hallinnon kehittämiskeskus. Helsinki. (Ensipainos 1995).

GONZÁLEZ, Norma. (1999) What Will We Do When Culture Does Not Exist Anymore? Anthropology \& Education Quarterly, Vol. 30, nro 4, pp. 431435.

GUIDELINES FOR PROGRAMME DESIGN, MONITORING AND EVALUATION. (1998) Ministry for Foreign Affairs (of Finland). Department for International Development Co-operation. Helsinki.

HESS Jr, G. Alfred. (1999) Keeping Educational Anthropology Relevant: Asking Good Questions Rather than Trivial Ones. Anthropology \& Education Quarterly, Vol. 30, nro 4, pp. 404-412.

JACOB, Evelyn. (1997) Context and Cognition. Implications for Educational Innovators and Anthropologists. Anthropology and Education Quarterly, Vol. 28, nro 1, pp. 3-21.

JARVIS, Peter. (1987) Adult Learning in the Social Context. Croom Helm. London.

JORDAN, B. (1989) Cosmopolitical Obstetrics: Some Insights from the Training of Traditional Midwives. Social Science and Medicine. Vol. 28, nro 9, pp. 925-944.

JUDÉN-TUPAKKA, S. (1993) Miten kehitysyhteistyöprojektin yhteistyöorganisaation suomalainen osapuoli konstruoi dayan, egyptiläisen kyläkätilön, oman työnsä kohteena? Helsingin yliopisto. Kasvatustieteen laitos. Aikuiskasvatustieteen syventävien opintojen tutkielma.

JUDÉN-TUPAKKA, S. (1995) Who is a Daya? Focusing the Work Content of an Egyptian Village Midwife Using Preanalysis of the Data Collected in Fieldwork. In: Adult Learning in a Cultural Context. Ed. A. Kauppi, S. Kontiainen, K. E. Nurmi, J. Tuomisto \& T. Vaherva. pp. 72-80. Adult Educational Research Society University of Helsinki, Lahti Research and Training Centre. Helsinki.

JUDÉN-TUPAKKA, S. (2000) Daya naisten maailman välittäjänä. Kehitysyhteistyöprojektiin osallistuneita yläegyptiläisiä kyläkätilöitä koskeva tutki- mus. Yliopistopaino. Helsinki.

KEHITYSYHTEISTYÖN PERIAATEPÄÄTÖS 1996. (1999) Ulkoasiainministeriön kehitysyhteistyöosasto tiedotusyksikkö.

LAITINEN, Hanna \& VOIPIO, Timo \& GRÖNQVIST, Maria. (1995) Yhteisön ääni. Kehitysyhteistyön Palvelukeskuksen julkaisusarja nro 15. Helsinki.

MEZIROW, Jack \& al. (1995) Uudistava oppiminen: Kriittinen reflektio aikuiskoulutuksessa. Helsingin yliopiston Lahden tutkimus- ja koulutuskeskus. Helsinki.

NURMI, Kari E. \& KONTIAINEN, Seppo. (1995) A Frame for Adult Learning and Cultural Context: Mediating Cultural Encounters. In: Adult Learning in a Cultural Context. Ed. A. Kauppi, S. Kontiainen, K. E. Nurmi, J. Tuomisto \& T. Vaherva. pp. 65-71. Adult Educational Research Society University of Helsinki, Lahti Research and Training Centre. Helsinki.

SEPPÄLÄ, Pekka \& VAINIO-MATTILA, Arja (1999) Navigating Culture. A Road Map to Culture and Development. Ministry for Foreign Affairs (of Finland). Department for International Development Co-operation. Helsinki.

SIIKALA, Anna-Leena. (1997) Toisiinsa virtaavat maailmat. Teoksessa: Kaukaa haettua. Kirjoituksia antropologisesta kenttätyöstä. Toim. Anna-Maria Viljanen \& Minna Lahti. s. 46-68. Suomen antropologinen seura. Helsinki.

SRINIVASAN, Lyra (S.A.) Tools for Community Participation. A Manual for Training Trainers I. Particpatory Techniques. UNDP. New York.

SUOMEN KEHITYSMAAPOLITIIKAN LINJAUS 1998. (1999) Ulkoasiainministeriö.

SWANTZ, Marja-Liisa \& Vainio-Mattila, Arja. (1988) Participatory Inquiry as an Instrument of Grassroots Development. In: Human Inquiry in Action. Developments in New Paradigm Research. Ed. Peter Reason. pp. 127-143. Sage Publications. London. Newbury Park. Beverly Hills.

TAKALA, Tuomas. (1989) Kehitysmaiden koulutusongelmia. Politica-sarja. Gaudeamus. Helsinki.

UUSI SIVISTYSSANAKIRJA. (1992) Toim. Annukka Aikio. Uusinut Rauni Vornanen. Otava. Helsinki.

VAINIO-MATTILA, Arja. (1999) Navigating Gender. A Framework and a Tool for Participatory Development. Ministry for Foreign Affairs (of Finland). Department for International Development Cooperation. Helsinki.

VAINIO-MATTILA, Arja. (1997/1996) Participation: Concept, Practice and Implications for Finnish Development Co-operation. Blue series 1997:1. Ministry of Foreign Affairs (of Finland). Department for International Development Co-operation. Helsinki.

WILD, Vicki \& Vainio-Mattila, Arja. (1995) International Training Package on Gender Analysis and Forestry. Food and Agriculture Organization. Rome.

Yllä oleva artikkeli perustuu Soila Judén-Tupakan lectioon. Hänen väitöstutkimuksensa "Daya naisten maailman välittäjänä" tarkastettiin Helsingin yliopiston kasvatustieteen laitoksella 31.3.2000 vastaväittäjinä kulttuuriantropologian dosentti Anna Maria Viljanen ja dosentti Rauni Räsänen. 